Article

\title{
Investigations of Mixing Technique on the Rheological Properties of Self-Compacting Concrete
}

\author{
Huajian Li ${ }^{1,2}$, Fali Huang ${ }^{1,2}$, Zhonglai $\mathrm{Yi}^{1,2}$, Zhen Wang ${ }^{1,2}$, Yong Zhang ${ }^{3,4, *(1)}$ \\ and Zhengxian Yang ${ }^{3, *(\mathbb{D})}$ \\ 1 Railway Engineering Research Institute, China Academy of Railway Sciences Corporation Limited, \\ Beijing 100081, China; lihuajian@rails.cn (H.L.); 18811789830@126.com (F.H.); yizhonglai@rails.cn (Z.Y.); \\ wangzhenbanana@163.com (Z.W.) \\ 2 State Key Laboratory of High Speed Railway Track Technology, Beijing 100081, China \\ 3 College of Civil Engineering, Fuzhou University, Fuzhou 350116, China \\ 4 Microlab, Section of Materials and Environment, Department of 3MD, Faculty of Civil Engineering \\ and Geosciences, Delft University of Technology, $2628 \mathrm{CN}$ Delft, The Netherlands \\ * Correspondence: y.zhang@fzu.edu.cn (Y.Z.); zxyang@fzu.edu.cn (Z.Y.)
}

Received: 21 June 2020; Accepted: 27 July 2020; Published: 28 July 2020

\begin{abstract}
Rheological properties are of significant importance in successful placement and performance of self-compacting concrete (SCC). In this work, the rheological properties of SCC, combined with a powder-viscosity modifying admixture, were investigated based on a series of experimental studies. The modified Bingham model was applied to determine the rheological parameters and shear thickening behavior of SCC. The effects of mixing procedures, including charging sequence, mixing time and mixing speed, were analyzed. The results show that the shear thickening of SCC is reduced by first mixing the aggregate and water and then adding other raw materials. The direct contact between aggregate and water leads to a large amount of free water to be adsorbed by the aggregate system, resulting in an increase of the yield stress. In order to ensure an excellent fluidity and a low shear thickening behavior of SCC, the mixing time should be controlled at $4-5 \mathrm{~min}$ and the mixing speed at $30-45 \mathrm{r} / \mathrm{min}$.
\end{abstract}

Keywords: self-compacting concrete; charging sequence; mixing time; mixing speed; rheological properties

\section{Introduction}

Production of a concrete that reaches compaction under its own weight is one of the significant advances in modern concrete technology. Self-compacting concrete (SCC) was first developed in Japan owing to the needs of procedures capable of promoting production [1]. The main advantages of SCC can be ascribed to its autogenous levelling and reaching a proper compaction, even when passing through the steel bars. Production of SCC mitigates the conventional means of compaction by vibration, hence leading to less noise and energy, as well as a reduction in labor cost and execution time [2].

The successful use of SCC is based on its high filling ability, high passing ability, and good stability [3,4]. The first concerns the ability of concrete to change its shape and flow around barriers. The second corresponds to the capability of passing narrow spaces. The third points to a high resistance against static segregation (separation of coarse aggregate and paste) and dynamic segregation (which takes place during transport and casting). SCC is characterized by a low yield value (to readily spread the concrete away from the discharge site) and a relatively high viscosity (to maintain a homogeneous dispersion). It normally contains a higher amount of fine powders than conventional concrete in order to achieve self-compaction. Utilizations of a viscosity modifying admixture (VMA), along with 
adequate superplasticizer, enable an excellent workability and an adequate segregation resistance while the concrete is pumped or cast into place until the onset of hardening [5].

The rheological properties of fresh SCC significantly influence the mechanical performances and durability properties of the concrete structures [6]. Rheology is the study of the flow of matter, primarily in a liquid state. In this respect, materials with complex microstructure are typically of high interest [7]. The formulation mostly applied for characterizing the steady-state rheological properties, with thixotropy [8] and workability loss not considered, is the well-known Bingham model [9]. This model provides a linear relationship between the shear rate $\dot{\gamma}[1 / \mathrm{s}]$ and the shear stress $\tau[\mathrm{Pa}]$ by introducing two variables, yield stress $\tau_{0}[\mathrm{~Pa}]$ and plastic viscosity $\mu[\mathrm{Pa} \cdot \mathrm{s}]$, as shown in Equation (1).

$$
\tau=\tau_{0}+\mu \dot{\gamma}
$$

It has been reported, however, that the rheological behavior of fresh SCC is non-linear. The apparent viscosity increases with an increase of the shear rate, i.e., shear thickening [4], and vice versa for the shear thinning $[10,11]$. The shear thickening behavior is particularly important at high shear rates when mixing and pumping. Significant shear thickening and shear thinning are undesirable to the engineering application of SCC [12].

In cases of a higher viscosity, a larger amount of energy is required to maintain adequate flow. In some cases [10], the yield stress extrapolated from the Bingham model is negative, which is in reality not possible. Since the non-linear behavior is often observed for SCC, the H-B (Herschel-Bulkley) model as shown in Equation (2) has been proposed. It is considered that the shear thickening appears when $n>1$ while the shear thinning appears when $n<1$, where the $n$ value indicates the degree of shear thickening response $[13,14]$. In addition, the modified Bingham model as shown in Equation (3) has also been put forward to describe the rheological properties of fresh SCC, with the shear thickening occurring if $c / \mu>0$ and the shear thinning occurring if $c / \mu<0$ [15].

$$
\begin{gathered}
\tau=\tau_{0}+K \dot{\gamma}^{n}\left(\tau \geq \tau_{0}\right), \\
\tau=\tau_{0}+\mu \dot{\gamma}+c \dot{\gamma}^{2},
\end{gathered}
$$

where $\tau$ is the shear stress in $\mathrm{Pa} ; \tau_{0}$ is the yield stress in $\mathrm{Pa} ; \mu$ is the plastic viscosity in $\mathrm{Pa} \cdot \mathrm{s} ; \dot{\gamma}$ is the shear rate in $1 / \mathrm{s} ; n$ is the flow index; $K$ is the consistency factor in Pa. $\mathrm{s}^{\mathrm{n}}$; and $\mathrm{c}$ is the second order parameter in $\mathrm{Pa} \cdot \mathrm{s}^{2}$.

The difficulties linked to homogeneously mixing SCC can be attributed to the peculiar mixture characteristics of "three high and one low" (high powder dosage, high admixture dosage, high superplasticizer dosage, and low water-powder ratio), as well as to the rheological characteristics of high fluidity. Compared with common concrete, SCC requires a longer mixing time to achieve homogeneity due to its high paste volume and low water-cement ratio. The time period required to achieve a uniform dispersion of a granular substance into a mix is associated with the particle size of the substance. Repartition of coarse aggregates is much faster than that of sand and fine cement particles [16]. The power consumption curve is often used as the index of concrete homogeneity. When the power curve attains a relatively stable state, the concrete reaches homogeneous state. The larger the water-powder ratio, the shorter the power consumption curve. The time period to reach homogeneity is also influenced by the content of fine powders and the amount of superplasticizer (SP).

Feys et al. [17] found that the cement paste wrapped aggregate method can significantly improve the fluidity of SCC. Dehn [18] and Chang et al. [19] stated that the SP subsequently added method can reduce the mixing time but is not favorable for the dispersion of SP. Hemalatha et al. [20] and Yamada et al. [21] reported that the SP subsequently added method can reduce the adsorption of SP molecules on the surface of cement particles, thereby improving the concrete workability. Such reduction is considered to be associated with the type of SP, as claimed by Qu et al. [22]. Naphthalene water reducer, relying on its electrostatic potential to resist congregation, has a great capability in flow 
ability. Polycarboxylate SP shows steric hindrance, readily leading to a dispersion between fine particles. This advantage has been confirmed previously by workers like Collepardi [23] and Uchikawa et al. [24]. According to the studies by Dils et al. [25], the water-powder ratio has an impact on the dispersion phenomenon as observed in the SP subsequently added method, and the slump-flow properties of the mixtures become increasingly sensitive with a higher water-powder ratio. Dehn [18] observed a higher fluidity, caused by a longer mixing time (3-7 $\mathrm{min}$ ), for ultra-high-performance concrete (UHPC). Nevertheless, over-mixing may wear off fine aggregates, thus lowering down the workability of the mixtures, a finding reported by Schiessl et al. [26]. Investigations from Collin et al. [27] and Mazanec et al. [28] indicated that a properly higher mixing speed could result in a shorter mixing time and meanwhile a larger mixing efficiency. On the other hand, adverse effects on the workability and rheological properties of concrete due to high-speed mixing have also been found. The main reason can be related to the fact that high-speed mixing may wear off aggregates and subsequently reduce the dispersion degree for both cement particles and SP [29,30].

Traditionally, infrastructures were built up by emphasizing design over construction. As such, the quality problems caused by poor workability of concrete are nowadays common. Self-compacting concrete (SCC), whose rheological properties are highly influential on the performances of cast-in-situ concrete structures, remains limited in practical applications. The combination type SCC, which possesses remarkable rheological properties and high robustness, has been utilized on a large scale in the CRTS III slab ballastless track of China's high-speed railway.

Plenty of publications have been reported on the influencing factors on rheological properties of concrete. Wallevik [31] evaluated the change of yield stress and viscosity as a function of the mix proportion of concrete. Incorporations of SP, which are crucial for self-compaction, to causing loss of yield stress have been intensively reported [31,32]. Admixtures can be included to increase the viscosity and further to keep the stability of SCC [33]. In Europe, limestone filler and fly ash are added frequently to reach a high amount of fine powders to maintain adequate viscosity. Other influencing factors such as water-binder ratio, viscosity modifying admixtures, and temperature have been well documented [34-36]. It is worthwhile to note that the results reported in the literature show a large scatter and are difficult to compare, with no standard mixing procedures having been established yet. SCC shows significantly higher sensitivity to small changes in the mixing procedures as compared to conventional vibrated concrete. Research on the effects of mixing procedures, including charging sequence, mixing time, and mixing speed, on the rheological properties of SCC is unfortunately not sufficient.

The present work aims at highlighting the significances of the mixing procedures to the rheological properties of SCC, by monitoring the variations of the slump-flow, yield stress, and torque. Both the H-B model and the modified Bingham model have been used to describe the shear thickening response of SCC, but the description of $c / \mu$ in the modified Bingham model is found to be more appropriate for evaluating the shear thickening response of SCC [37]. The modified Bingham model will therefore be adopted in this work. The research reported herein is necessary to capture the basic factors that can affect the performances of SCC in practice. Results of the present work will help to provide valuable information for the solutions to the robustness of SCC in the infrastructure construction.

\section{Experimental}

\subsection{Materials and Mix Proportions}

The raw materials used for SCC consisted of ordinary Portland cement (P.O 42.5), fly ash, ground granulated blast furnace slag, calcium oxide-calcium sulphoaluminate composite expansive agent, river sand with a fineness modulus of 2.6, and crushed limestone aggregate with a continuous-grading of $5-20 \mathrm{~mm}$. The polycarboxylate SP with a density of $1050 \mathrm{~kg} / \mathrm{m}^{3}$ was used to achieve desired slump-flow. The rosin resin type air entraining agent was used to achieve expected air content. The viscosity modifying admixture (VMA), composing of mineral admixtures and cellulose ether, was used to avoid 
segregation. The physical properties and chemical compositions of the cement, slag powder and fly ash are shown in Table 1. The mix proportions are shown in Table 2.

Table 1. Physical properties and chemical composition of cement, slag powder and fly ash.

\begin{tabular}{|c|c|c|c|c|c|c|c|c|}
\hline Items & Loss of Ignition/\% & $\mathrm{SO}_{3} / \%$ & $\mathrm{Cl}^{-} / \%$ & $\mathrm{Na}_{2} \mathrm{O}+\mathrm{K}_{2} \mathrm{O} / \%$ & $\mathrm{f}-\mathrm{CaO} / \%$ & $\mathrm{MgO} / \%$ & $\begin{array}{l}\text { Specific Surface } \\
\text { Area/ }\left(\mathbf{m}^{2} \cdot \mathrm{kg}^{-1}\right)\end{array}$ & Density $/\left(\mathrm{g} \cdot \mathrm{cm}^{-3}\right)$ \\
\hline Cement & 2.97 & 2.39 & 0.016 & 0.63 & 0.71 & 3.32 & 364 & 3.08 \\
\hline Slag & 0.18 & 1.46 & 0.012 & 0.44 & / & 12.72 & 301 & 2.86 \\
\hline Fly ash & 3.97 & 0.41 & 0.006 & 0.65 & 0.03 & 1.65 & 438 & 2.21 \\
\hline
\end{tabular}

Table 2. Mix proportions of self-compacting concrete (SCC) in $\mathrm{kg} \cdot \mathrm{m}^{-3}$. VMA—viscosity modifying admixture; SP-superplasticizer.

\begin{tabular}{cccccccccc}
\hline Cement & Fly Ash & Slag & Expansive Agent & VMA & Coarse Aggregate & Sand & Water & SP & Air-Entraining Agent \\
\hline 250 & 63 & 159 & 47 & 0.78 & 747 & 913 & 182 & 4.75 & 0.075 \\
\hline
\end{tabular}

\subsection{Samples Preparation}

Samples preparation was carried out in a single campaign. Particular attention was paid to maintaining a stable mixing environment to avoid unintentional discrepancy. An HJW-60 type single horizontal-axis forced mixer was used to prepare the SCC samples, each with a batch of $40 \mathrm{~L}$ and about $30 \mathrm{~L}$ was used for rheology measurements. Different mixing procedures and subsequently resultant rheological properties were studied. Five different charging sequences, from No. A to No. E as displayed below, were examined in order to understand their effect on the performance of fresh SCC:

- No. A (ready-mixed dry materials method): All dry components (aggregates, cementitious materials, etc.) were firstly mixed for $30 \mathrm{~s}$. Then SP, air-entraining agent, and water were added and mixed for another $3 \mathrm{~min}$.

- No. B (SP subsequently added method): All dry components (aggregates, cementitious materials, etc.) and $3 / 4$ of the water content were firstly mixed for $30 \mathrm{~s}$. Then SP, air-entraining agent and the remaining water were added and mixed for another $150 \mathrm{~s}$.

- No. C (Binding sand method): The sand and 3/4 of the water content were first mixed for $30 \mathrm{~s}$. Then cementitious materials were added and mixed for another 30 s. Finally, SP, air-entraining agent and the remaining water were added, and mixed for another $150 \mathrm{~s}$.

- No. D (Shell making with coarse and fine aggregate method): Aggregates and 3/4 of the water content were first mixed for $30 \mathrm{~s}$. Next, cementitious materials were added and mixed for another $30 \mathrm{~s}$. Finally, SP, air-entraining agent, and the remaining water were added and mixed for another $150 \mathrm{~s}$.

- No. E (Cement paste wrapped sand method): Cementitious materials and 3/4 of the water content were first mixed for $30 \mathrm{~s}$. Then, aggregates were added and mixed for another $30 \mathrm{~s}$. Finally, SP, air-entraining agent, and the remaining water were added and mixed for another $120 \mathrm{~s}$.

In parallel, four different mixing time periods including $2 \mathrm{~min}, 3 \mathrm{~min}, 4 \mathrm{~min}$, and $5 \mathrm{~min}$ were executed to capture the effect of mixing time on concrete performances. What's more, in order to study the effect of mixing speed on concrete performances, four variable mixing speeds were implemented, i.e., $15 \mathrm{r} / \mathrm{min}, 30 \mathrm{r} / \mathrm{min}, 45 \mathrm{r} / \mathrm{min}$, and $60 \mathrm{r} / \mathrm{min}$. Note that the ready mixed dry materials method (charging sequence No. A) was selected to study the effect of mixing time and mixing speed on the rheological properties of SCC.

\subsection{Rheological Measurement}

Measurements of concrete rheology are complicated because of the presence of large aggregates. To mitigate the negative effect of large aggregates, one possible solution is to entail a specimen sufficiently large. This has been achieved usually by enlarging the gap between the inner and the outer cylinders of the mold, i.e., at least 3-5 times the size of the coarse aggregates [38]. In this work, 
the rheological measurements were carried out by using the RHM-3000 ICAR rheometer, which was equipped with cylindrical spindles. The vane height was $290 \mathrm{~mm}$. The diameter and height of the outer cylinder were $355 \mathrm{~mm}$ and $380 \mathrm{~mm}$, respectively. The outer cylinder was installed with ribs to prevent possible slippage during the tests. Rheometer operation and measurements were computer controlled.

Yield stress and plastic viscosity play important roles in the material deformability and stability. To alleviate the impact of thixotropy, a pre-shearing period (about $20 \mathrm{~s}$ with $0.50 \mathrm{rps}$ ) was set before testing and meanwhile attempting to reduce the speed step by step in the tests. The tests were performed stepwise at 10 different speeds $(0.50 \mathrm{rps}, 0.45 \mathrm{rps}, 0.40 \mathrm{rps}, 0.35 \mathrm{rps}, 0.30 \mathrm{rps}, 0.25 \mathrm{rps}$, $0.20 \mathrm{rps}, 0.15 \mathrm{rps}, 0.10 \mathrm{rps}, 0.05 \mathrm{rps})$. The raw data of torque and apparent viscosity were recorded and then converted into shear stress $\tau$ and shear rate $\dot{\gamma}$, respectively. The yield stress $\tau_{0}$ and the plastic viscosity $\mu$, as well as the parameter $c$, can be determined subsequently from regression analysis with the modified Bingham model (Equation (3)). Each test was completed within $70 \mathrm{~s}$; hence, the impact of the slump-flow loss and the aggregate transfer on the test results can reasonably be ignored.

\section{Results and Discussion}

\subsection{Effect of Charging Sequence on Rheological Properties of SCC}

It has been recognized that the fluidity of ordinary cement pastes can be improved by retarding the addition of SP. Early addition of SP can easily result in part of the SP to be wrapped by the early cement hydration products, reducing the effective content of SP. This disadvantage can be avoided when the SP is added in the later mixing stage [18].

Figure 1 shows the slump-flow of SCC prepared under five different charging sequences. As can be seen, the slump-flow of SCC by charging sequence No. A is obviously higher than that by charging sequence No. B. It seems that the conclusions mentioned above are not entirely applicable in the case of SCC. This may be due to the fact that the mixing time is shorter after the addition of SP, and the dispersant of SP is not uniform. In charging sequence No. C, by first mixing the sand and 3/4 of the water content for $30 \mathrm{~s}$ and then adding other raw materials, adsorption of a large amount of free water to the sand will be promoted, resulting in a decrease of the slump-flow of SCC. By first mixing the sand, coarse aggregate and $3 / 4$ of the water content for $30 \mathrm{~s}$ and then adding other raw materials, charging sequence No. D will lead to an extra increase in the water adsorption by aggregate and hence further decrease the fluidity of the SCC. The charging sequence No. E, where the cementitious materials and water were mixed first and the other raw materials were added thereafter, avoids direct contact between aggregates and water. As a consequence, adsorption of the free water to aggregate surface is hindered significantly and the fluidity of the SCC is improved. On the other hand, due to the short mixing time after adding SP, the slump-flow of the SCC by charging sequence No. E shows a slight decrease, compared to that by charging sequence No. A.

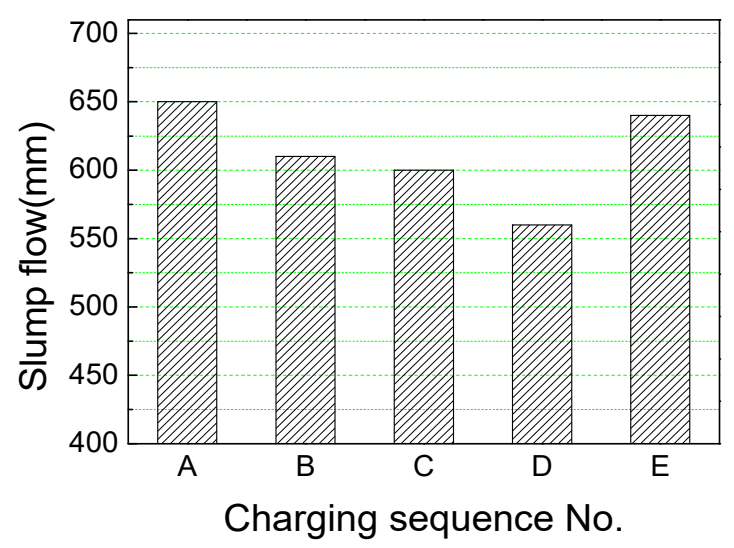

Figure 1. Effect of charging sequence on the slump-flow of self-compacting concrete (SCC). 
Figure 2 shows the effect of the charging sequence on the rheological parameters of the SCC. Combinations of Figures 1 and 2 reveal that a larger slump-flow corresponds to a smaller yield stress. An approximately linear relationship has been found between the two parameters, as shown in Figure 3 . The plastic viscosity is relatively larger when the SCC was prepared by the charging sequence No. B (SP subsequently added method) than by the No. A. This is a result of the shorter mixing time of SP, whereby the dispersing effect of SP was weakened and the volume of free water was reduced. A further increase of the plastic viscosity is observed when the SCC was obtained by the charging sequence No. C. As a matter of fact, a direct contact of the sand with the water can result in a considerable reduction in free water content due to the impact of the water adsorption by the sand. Of particular interest to note is that the plastic viscosity by charging sequence No. D is apparently lower than that by charging sequence No. A. This probably results from the friction and collision between aggregate particles in the mixing process, reflected by a decrease of the flow resistance as well as a decrease of the plastic viscosity. It should be mentioned that charging sequence No. E results in the smallest plastic viscosity. This is reasonable against the background of interface physics. By first mixing a large amount of water with cementitious materials, a paste with low water-powder ratio will be produced and, as a consequence, the water adsorption of aggregate after its addition is greatly reduced and thus the free water content is increased, leading to a higher fluidity and a lower plastic viscosity.

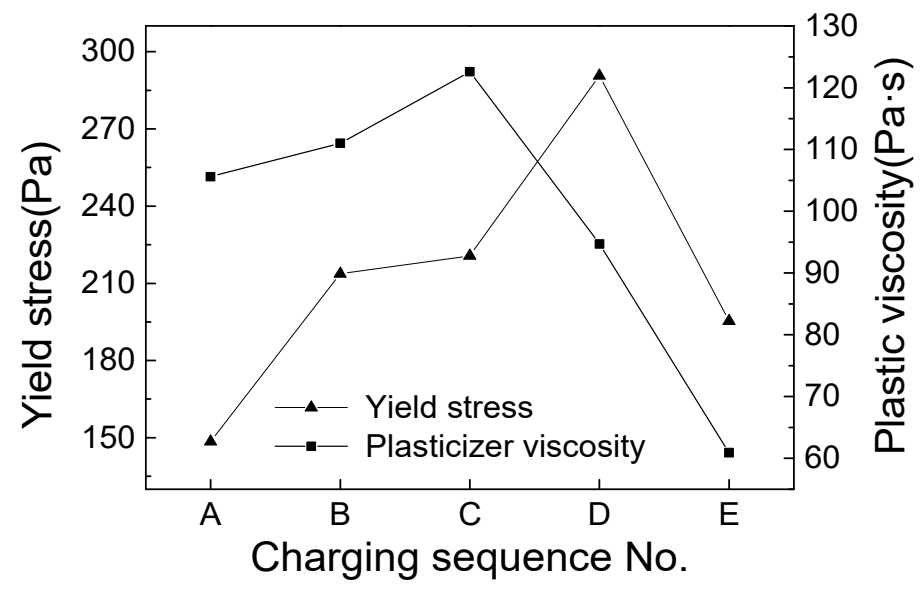

Figure 2. Effect of charging sequence on the rheological parameters of SCC.

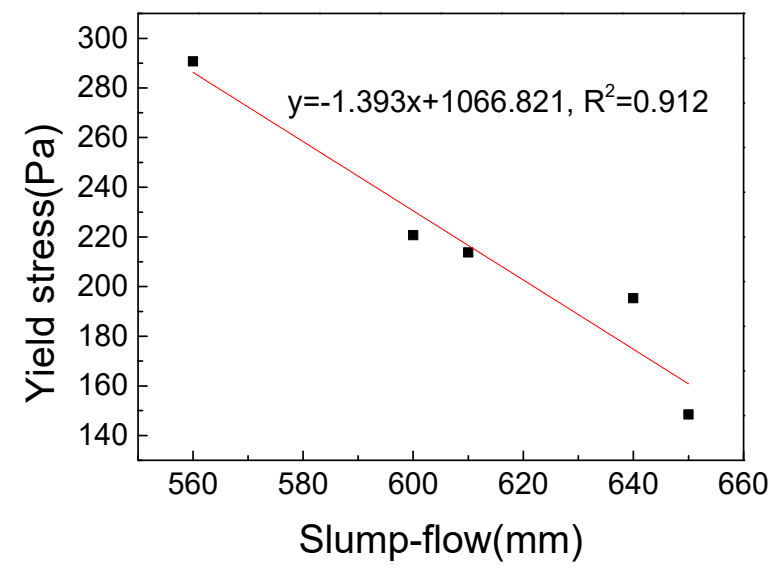

Figure 3. Relationship between the slump-flow and the yield stress of SCC.

Figure 4a shows the rheological curves of SCC versus different charging sequence obtained by fitting with the modified Bingham model (Equation (3)). As can be seen, these rheological curves are all concave in shape. As such, the shear thickening behavior has taken place for these SCC mixtures. Similar tendencies of the torque-speed pattern can be observed in all cases. These tendencies are 
numerically addressed in the relations shown in Figure $4 \mathrm{a}$. Figure $4 \mathrm{~b}$ presents the relationship between the $c / \mu$ and the charging sequence. The values of $c / \mu$ differ slightly but are much higher in the cases of No. A, B and E, indicating a more significant shear thickening behavior, than in the cases of No. C and D. The three charging sequences (No. A, B, and E) have one point in common that the cementitious pastes, by directly contacting the water, are able to hydrate sufficiently. The aggregation kinetics among particle networks can thus distribute towards a more orderly state. However, the paste matrix can break down, under the shear stress, and the degree of disorder subsequently increases. As a result, the shear thickening behavior of the SCC mixtures occurs by following the order-disorder transition theory [39].

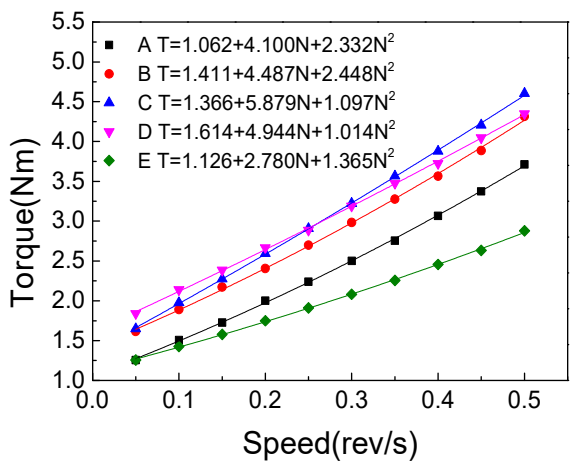

(a) Torque vs. speed

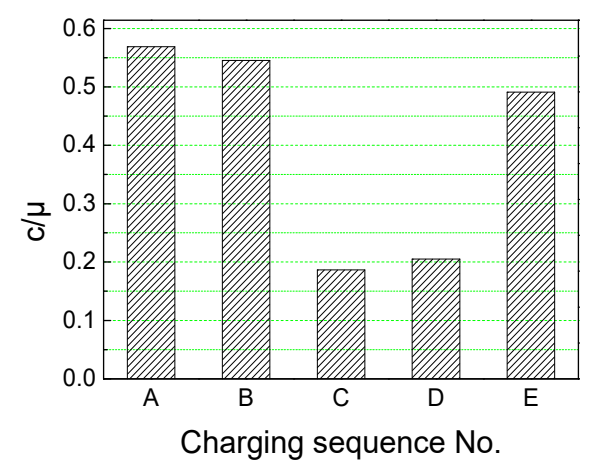

(b) $c / \mu$ vs. charging sequence

Figure 4. Effect of charging sequence on the shear thickening behaviour of SCC.

\subsection{Effect of Mixing Time on Rheological Properties of SCC}

Figure 5 shows the slump-flow of SCC at different mixing time period. It is obvious that an increase of the mixing time leads to a higher slump-flow. However, once the mixing time reaches 4 $\mathrm{min}$, a further increase of the mixing time will not increase the slump-flow of the SCC, i.e., attaining the plateau after $4 \mathrm{~min}$. Figure 6 presents the changes of the rheological parameters with mixing time. In a general trend, both the yield stress and the plastic viscosity decrease with a longer mixing time. This is acceptable in view of the high content of SP and low water-powder ratio of SCC. A short mixing time is not favorable to the dispersion of the components, especially to the dispersion of the SP, resulting in a smaller slump-flow of the SCC mixtures [18]. With the prolongation of mixing time, the components in the mixtures is more sufficiently mixed. The SP can then be better dispersed and gradually achieve the best water reducing effect, and a maximum slump-flow of the mixture is eventually reached. From this moment onward, further extending the mixing time will lead to the state of "over mixing," and the slump-flow of the SCC mixtures can be slightly decreased afterward. This is a result primarily from the friction and extrusion of the coarse aggregates, whereby the particle size decreases, the surface roughness increases, and the water demand increases $[40,41]$.

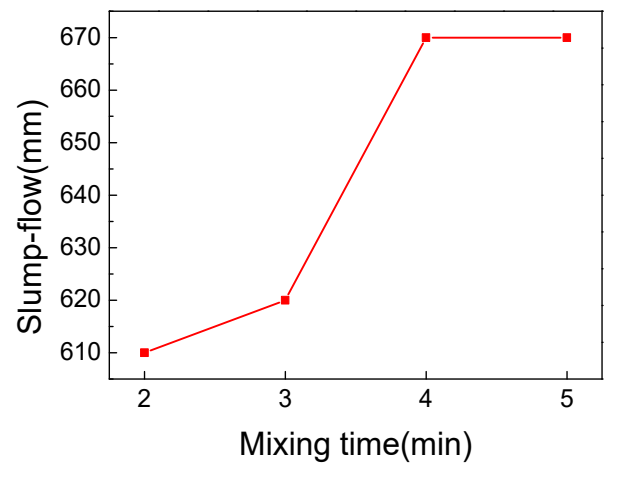

Figure 5. Effect of mixing time on the slump-flow of SCC. 


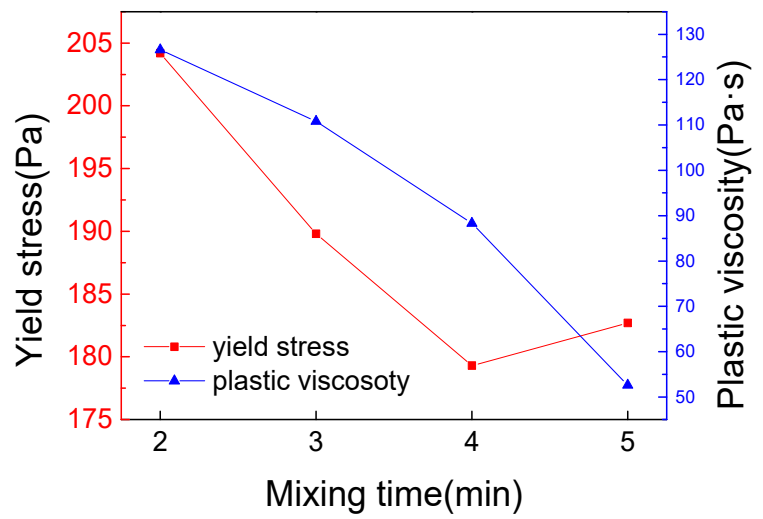

Figure 6. Effect of mixing time on the rheological parameters of SCC.

On basis of the modified Bingham model, the rheological curves of SCC with different mixing time were determined. The results are presented in Figure 7a. An obvious observation points to the shear thickening behavior in all the SCC mixtures, a finding similar to that as drawn from Figure 4a. Figure $7 \mathrm{~b}$ presents the relationship between $c / \mu$ and mixing time. The value of $c / \mu$ shows a decreasing trend with the increase of mixing time. It is a direct evidence supporting that a longer mixing time can weaken the shear thickening behavior of SCC. In this regard two aspects are responsible. First, with a very short mixing time, the particles present in a high heterogeneity inside the mixture and are in a disordered distribution state. Under the action of shear stress, the granular system changes gradually towards to the ordered distribution state and correspondingly the interference between particles decreases. Second, the SP disperses unevenly in a short mixing time and it is more prone to intertwine under shear stress. The degree of disorder will therefore increase, resulting in a further enhancement of the shear thickening behavior of the mixtures.

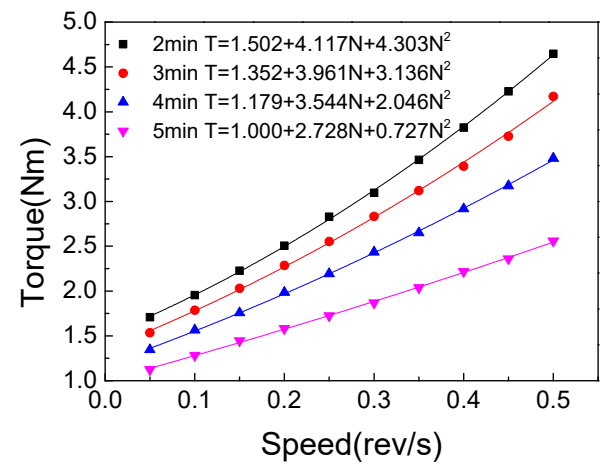

(a) Torque vs. speed

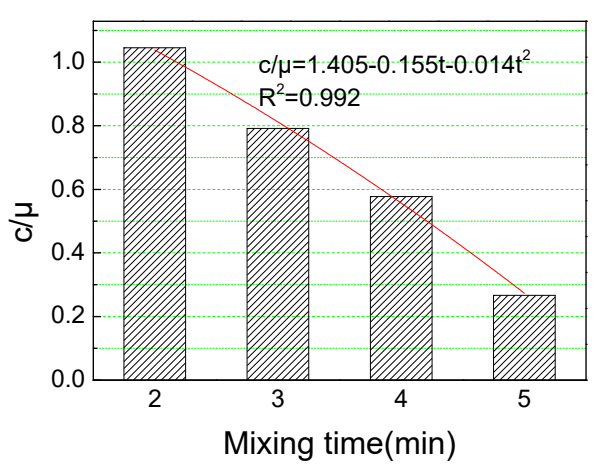

(b) $\mathrm{c} / \mu$ vs. mixing time

Figure 7. Effect of mixing time on shear thickening behaviour of SCC.

In order to speculate the critical mixing time at which the transition of shear thickening to shear thinning could occur, the values of $c / \mu$ are plotted as a function of the mixing time, as shown in Figure $7 \mathrm{~b}$. On curve-fitting basis, an expression given in Equation (4) can be obtained. In case the $c / \mu$ is set as zero, the mixing time equates at around $5.9 \mathrm{~min}$, which is defined as the critical mixing time for the transition of shear thickening to shear thinning.

$$
c / \mu=1.405-0.155 t-0.014 t^{2},
$$

where $t[\mathrm{~min}]$ is the mixing time. 


\subsection{Effect of Mixing Speed on Rheological Properties of SCC}

Figure 8 shows the results of the effect of mixing speed on the slump-flow of SCC. A drastic drop in the slump-flow with increasing mixing speed is observed. This observation provides new insights into the concrete rheological properties, after appraising the previously published results. According to the literature [42-44], at low level mixing speed, the fluidity of common cement pastes was found to be increased with increasing the mixing speed. At high level mixing speed, as reported by Han and Ferron [45], among others, the fluidity of common cement pastes was decreased with an increase of the mixing speed.

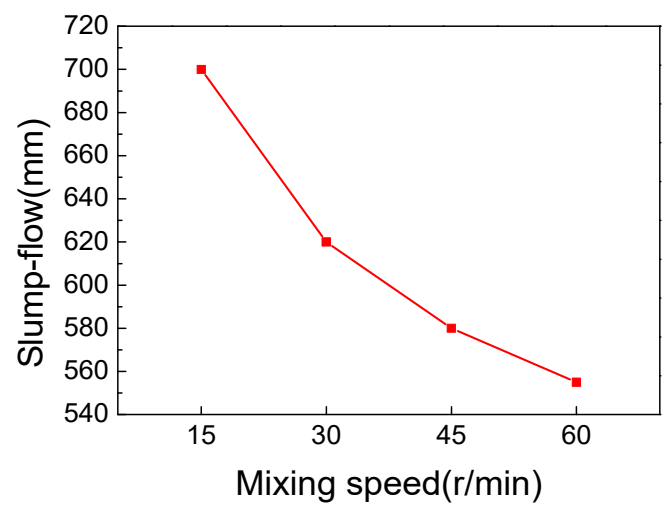

Figure 8. Effect of mixing speed on the slump-flow of SCC.

Obviously, at low level mixing speed, the fluidity of SCC is completely different from that of common cement pastes. This difference is attributable to the following aspects. First, the cementitious materials and SP suffer from the disturbance and shear force, exerted by the coarse aggregates. The actual mixing speed of the SCC can be approximately 2.5 times that of the equivalent paste mixing speed. Hence, the effect of mixing speed, at low levels, on the fluidity of SCC should be phenomenally judged as that, at high levels, on the fluidity of common cement pastes $[30,46]$. Second, as continuous increase of the mixing speed, the SCC mixtures become increasingly condensed, and the fluidity correspondingly decreases. Third, mixing at a high speed can readily cause the SP molecules to intertwine, subsequently impairing their water-reducing effect and weakening the fluidity of the mixtures. Fourth, since the SP has a poor adsorption capacity [39,47], it is reasonable to consider that with continuous increase of the mixing speed, the desorption phenomenon of the SP molecules becomes increasingly pronounced. As a result, the SP gradually loses its function as a water reducer and the fluidity of the SCC system turns to be weakened.

Figure 9 displays the effect of mixing speed on the rheological parameters of SCC. As observed, the yield stress increases significantly with the increase of mixing speed. The plastic viscosity, however, exhibits a completely different trend, and it decreases in the opposite sense.

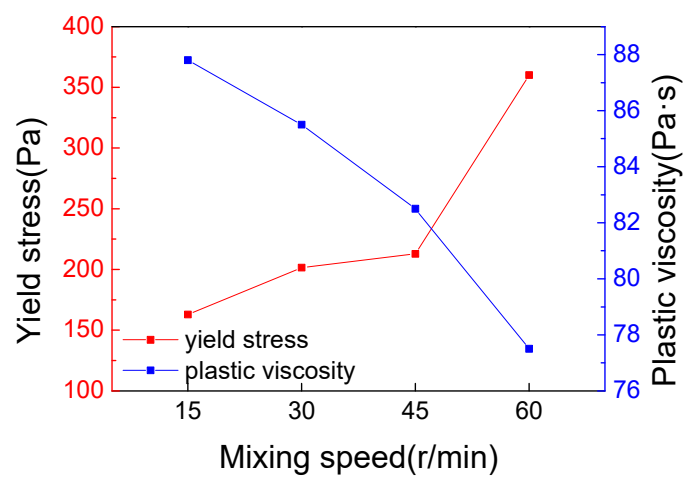

Figure 9. Effect of mixing speed on the rheological parameters of SCC. 
The rheological properties of SCC with different mixing speed, determined by curve-fitting of the modified Bingham model, are shown in Figure 10a. In the range of $15-45 \mathrm{r} / \mathrm{min}$, the rheological curves all exhibit concave pattern, which proves the occurrence of the shear thickening behavior. Interestingly to note is that the rheological curves suddenly turn into convex pattern for mixing speed at $60 \mathrm{r} / \mathrm{min}$, indicating the transition of shear thickening to shear thinning. Figure 10b shows the relationship between $c / \mu$ and mixing speed. It is obvious that the $c / \mu$ value decreases with the increase of mixing speed. This observation suggests that increasing the mixing speed can weaken the shear thickening behavior of SCC.

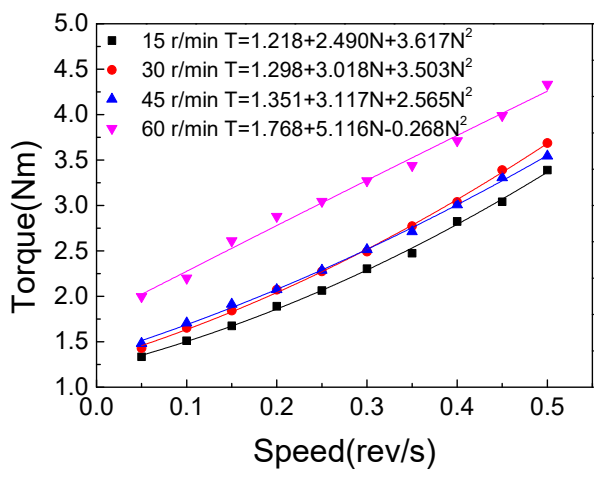

(a) Torque vs. speed

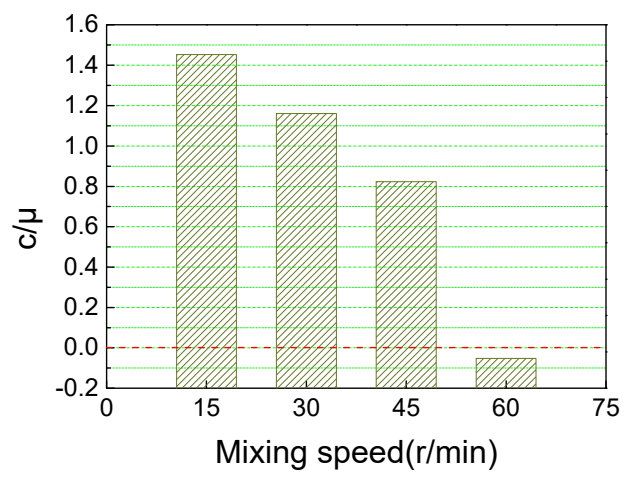

(b) $\mathrm{c} / \mu$ vs. mixing speed

Figure 10. Effect of mixing speed on the shear thickening behavior of SCC.

The smaller the mixing speed, the more stable the sorbent. As the mixing speed is continuously increased, desorption of the SP molecules becomes more significant, and the shear thickening behavior of the SCC mixtures is concurrently weakened. Once the mixing speed is sufficiently high, the desorption phenomenon dominates the behavior of the SP molecules in mixing process. Under the disturbance of shear stress, re-adsorption of the SP molecules can take place, resulting in shear thinning behavior of the SCC mixtures [39].

\section{Conclusions}

Systematic experiments have been carried out to characterize the effects of mixing procedures, including charging sequence, mixing time, and mixing speed, on the rheological properties of self-compacting concrete (SCC). The slump-flow, yield stress, plastic viscosity, and shear thickening behavior have been analyzed and discussed in detail. As a result of this investigation, the following conclusions are derived.

(1) The shear thickening of SCC is reduced by first mixing the aggregates with water and then adding other raw materials. On the other hand, the direct contact between aggregates and water results in a large amount of free water to be adsorbed by the aggregate system and therefore increases the yield stress of SCC.

(2) Short mixing time within 4 min leads to heterogeneous distribution of various components, resulting in high yield stress and plastic viscosity of the SCC mixtures. Prolonging the mixing time weakens the shear thickening of SCC. A critical mixing time of SCC from shear thickening to shear thinning is found to be $5.9 \mathrm{~min}$. Over mixing results in a poor fluidity of SCC. The mixing time is recommended to be controlled at $4-5 \mathrm{~min}$ in order for favorable rheological properties of SCC.

(3) Increasing the mixing speed weakens the shear thickening behavior of SCC. The yield stress and plastic viscosity of the SCC will be simultaneously reduced. In order to ensure an excellent 
fluidity and a low shear thickening behavior, the mixing speed of SCC should be controlled within the range of $30-45 \mathrm{r} / \mathrm{min}$.

Author Contributions: Writing—original draft preparation and conceptualization, H.L.; formal analysis and data curation, F.H.; investigation and resources, Z.Y. (Zhonglai Yi); visualization and validation, Z.W.; supervision, writing-review and editing, Y.Z.; methodology and project administration, Z.Y. (Zhengxian Yang). All authors have read and agreed to the published version of the manuscript.

Funding: This research was funded by the National Key R\&D Plan of China (Grant No. 2017YFB0310100), the National Natural Science Foundation of China (Grant No. U1934206 and 51578545), and the Technological Research and Development Programs of China Railways Corporation (Grant No. 2017G006-J, N2018G029 and J2017G001).

Acknowledgments: The authors are grateful to the State Key Laboratory of High Speed Railway Track Technology and Fujian Provincial University Research Center for Advanced Civil Engineering Materials. Both provided technical support for the experimental work.

Conflicts of Interest: The authors declare no conflict of interest.

\section{References}

1. Ozawa, K.; Mackawa, K.; Kunishima, M.; Okamura, H. High performance concrete based on the durability design of concrete structures. In Proceedings of the Second East-Asia and Pacific conference on Structural Engineering and Construction (EASEC-2), Chiengmai, Thailand, 26-28 January 1989; pp. 445-450.

2. Li, H.J. Technology of Self-Compacting Concrete Used for High-Speed Railway; Chemical Industry Press: Beijing, China, 2018. (In Chinese)

3. Yurugi, M. Application of self-compacting concrete in Japan. In Proceedings of the 23rd OWICS Conference, CI-Premier, Singapore, 25-26 August 1998; pp. 29-42.

4. Skarendahl, A.; Petersson, Ö. Self-Compacting Concrete, State-of-the Art Report of RILEM Technical Committee 174-SCC, Self-Compacting Concrete; RILEM Publications: Bagneux, France, 1999; p. 141.

5. Warner, J. Preplaced-aggregate concrete. Concr. Int. 2005, 27, 34-38.

6. Khayat, K.H. Workability, testing, and performance of self-consolidating concrete. ACI Mater. J. 1999, 96, 346-353.

7. Hamed, S.B.; Belhadri, M. Rheological properties of biopolymers drilling fluids. J. Petrol. Sci. Eng. 2009, 67, 84-90. [CrossRef]

8. Tattersall, G.H.; Banfill, P.F.G. The Rheology of Fresh Concrete; Pitman: London, UK, 1983.

9. Bingham, E.C. Fluidity and Plasticity; McGraw-Hill Book Company Incorporated: New York, NY, USA, 1922.

10. Feys, D.; Verhoeven, R.; De Schutter, G. Fresh self-compacting concrete, a shear thickening material. Cem. Concr. Res. 2008, 38, 920-929. [CrossRef]

11. Feys, D.; Verhoeven, R.; De Schutter, G. Why is fresh self-compacting concrete shear thickening. Cem. Concr. Res. 2009, 39, 510-523. [CrossRef]

12. Huang, F.L.; Li, H.J.; Yi, Z.L. The rheological properties of self-compacting concrete containing superplasticizer and air-entraining agent. Constr. Build. Mater. 2018, 166, 833-838. [CrossRef]

13. De Larrard, F.; Ferraris, C.F.; Sedran, T. Fresh concrete: A Herschel-Bulkley material. Mater. Struct. 1998, 31, 494-498. [CrossRef]

14. Heirman, G.; Hendrickx, R.; Vandewalle, L. Integration approach of the couette inverse problem of powder type self-compacting concrete in a wide-gap concentric cylinder rheometer Part II. Influence of mineral additions and chemical admixtures on the shear thickening flow behavior. Cem. Concr. Res. 2009, 39, 171-181. [CrossRef]

15. Yahia, A.; Khayat, K.H. Analytical models for estimating yield stress of high-performance pseudoplastic grout. Cem. Concr. Res. 2001, 31, 731-738. [CrossRef]

16. Johansson, A. The relationship between mixing time and type of concrete mixer. In Proceedings Handlingar; Swedish Cement and Concrete Research Institute: Stockholm, Sweden, 1971.

17. Feys, D.; Asghari, A.; Ghafari, E.; Ley Hernandez, A.M.; Van Der Vurst, F.; De Schutter, G. Influence of Mixing Procedure on Robustness of Self-Consolidating Concrete, a National University Transportation Center at Missouri University of Science and Technology; Report NUTC R333; Missouri University of Science and Technology: Washington, DC, USA, 2014; pp. 42-47. 
18. Dehn, F. Influence of mixing technology on fresh concrete properties of HPFRCC. In Proceedings of the International RILEM Workshop on HPFRCC in Structural Applications, Honolulu, HI, USA, 23-26 May 2005; pp. 1-8.

19. Chang, P.K.; Peng, Y.N. Influence of mixing techniques on properties of high performance concrete. Cem. Concr. Res. 2001, 31, 87-95. [CrossRef]

20. Hemalatha, T.; Sundar, K.R.R.; Murthy, A.R.; Lyer, N.R. Influence of mixing protocol on fresh and hardened properties of self-compacting concrete. Constr. Build. Mater. 2015, 98, 119-127. [CrossRef]

21. Yamada, K. Basics of analytical methods used for the investigation of interaction mechanism between cement and superplasticizers. Cem. Concr. Res. 2011, 41, 793-798. [CrossRef]

22. Qu, J.D.; Peng, J.H.; Chen, M.F. Review on the adsorption characteristic of superplasticizers on the surface of cement particles. J. Build. Mater. 2005, 4, 410-416. (In Chinese)

23. Collepardi, M. Admixtures used to enhance placing characteristics of concrete. Cem. Concr. Compos. 1998, 20, 103-112. [CrossRef]

24. Uchikawa, H.; Sawaki, D.; Hanehara, S. Influence of kind and added timing of organic admixture on the composition, structure and property of fresh cement paste. Cem. Concr. Res. 1995, 25, 353-364. [CrossRef]

25. Dils, J.; De Schutter, G.; Boel, V. Influence of mixing procedure and mixer type on fresh and hardened properties of concrete: A review. Mater. Struct. 2012, 45, 1673-1683. [CrossRef]

26. Schiessl, P.; Mazanec, O.; Lowke, D. SCC and UHPC—Effect of mixing technology on fresh concrete properties. In Advances in Constructions Materials 2007, Symposium in Honour of H.W. Reinhardt; University of Stuttgart: Stuttgart, Germany, 2007; pp. 513-522.

27. Jézéquel, P.H.; Collin, V. Mixing of concrete or mortars: Distributive aspects. Cem. Concr. Res. 2007, 37, 1321-1333. [CrossRef]

28. Mazanec, O.; Lowke, D.; Schiessl, P. Mixing of high performance concrete: Effect of concrete composition and mixing intensity on mixing time. Mater. Struct. 2010, 43, 357-365. [CrossRef]

29. Han, D. Flow Behavior and Microstructure of Cement-Based Materials. Ph.D. Thesis, The University of Texas, Austin, TX, USA, 2014.

30. Han, D.; Ferron, R.D. Influence of high mixing intensity on rheology, hydration, and microstructure of fresh state cement paste. Cem. Concr. Res. 2016, 84, 95-106. [CrossRef]

31. Wallevik, O.H. Course on the Rheology of Cement Based Particle Suspensions; BBRI: Copenhagen, Denmark, 2007.

32. Flatt, R.J. Towards a prediction of super-plasticized concrete rheology. Mater. Struct. 2004, 27, 289-300. [CrossRef]

33. De Schutter, G.; Bartos, P.; Domone, P.; Gibbs, J. Self-Compacting Concrete; Whittles Publishing: Scotland, UK, 2008.

34. Petit, J.Y.; Khayat, K.H.; Wirquin, E. Coupled effect of time and temperature on variations of plastic viscosity of highly flowable mortar. Cem. Concr. Res. 2009, 39, 65-170. [CrossRef]

35. Yahia, A.; Tanimura, M.; Shimoyama, Y. Rheological properties of highly flowable mortar containing limestone filler-effect of powder content and W/C ratio. Cem. Concr. Res. 2005, 35, 532-539. [CrossRef]

36. Esmaeilkhanian, B.; Khayat, K.H.; Yahia, A.; Feys, D. Effects of mix design parameters and rheological properties on dynamic stability of self-consolidating concrete. Cem. Concr. Compos. 2014, 54, 21-28. [CrossRef]

37. Li, H.J.; Huang, F.L.; Xie, Y.J. Effect of water-powder ratio on shear thickening response of SCC. Constr. Build. Mater. 2017, 131, 585-591. [CrossRef]

38. Brower, L.E.; Ferraris, C.F. Comparison of concrete rheometers. Concr. Int. 2003, 25, 41-47.

39. Ferron, R.D.; Shah, S.; Fuente, E.; Negro, C. Aggregate and breakage kinetics of fresh cement paste. Cem. Concr. Res. 2013, 50,1-10. [CrossRef]

40. Lowke, D.; Schiessl, P. Effect of mixing energy on fresh properties of SCC. In Proceedings of the 4th International RILEM Symposium on Self-Compacting Concrete, Chicago, IL, USA, 1-3 January 2005; pp. 1-7.

41. Lecompte, T.; Perrot, A.; Picandet, V.; Bellegou, H.; Amziane, S. Cement-based mixes: Shearing properties and pore pressure. Cem. Concr. Res. 2012, 42, 139-147. [CrossRef]

42. Yang, M.; Jennings, H.M. Influences of mixing methods on the microstructure and rheological behavior of cement paste. Adv. Cem. Based. Mater. 1995, 2, 70-78. [CrossRef]

43. Williams, D.A.; Saak, A.W.; Jennings, H.M. The influence of mixing on the rheology of fresh cement paste. Cem. Concr. Res. 1999, 29, 1491-1496. [CrossRef] 
44. Roy, D.M.; Asaga, K. Rheological properties of cement mixes: III. The effects of mixing properties on viscometric properties of mixes containing superplasticizers. Cem. Concr. Res. 1979, 9, 731-739. [CrossRef]

45. Han, D.; Ferron, R.D. Effect of mixing method on microstructure and rheology of cement paste. Constr. Build. Mater. 2015, 93, 278-288. [CrossRef]

46. Roussel, N. Correlation between yield stress and slump: Comparison between numerical simulations and concrete rheometers results. Mater. Struct. 2006, 39, 501-509. [CrossRef]

47. Wallevik, J.E. Rheology of Particle Suspensions: Fresh Concrete, Mortar and Cement Paste with Various Types of Lignosulfonates. Ph.D. Thesis, Norwegian University of Science and Technology, Trondheim, Norway, 2003; pp. 24-32.

(C) 2020 by the authors. Licensee MDPI, Basel, Switzerland. This article is an open access article distributed under the terms and conditions of the Creative Commons Attribution (CC BY) license (http://creativecommons.org/licenses/by/4.0/). 